\title{
Carbon Retention in the Soil-plant System under different Irrigation Regimes
}

Wang, Yaosheng; Liu, Fulai; Andersen, Mathias Neumann; Jensen, Christian Richardt

Published in:

Proceedings: the 2nd International Workshop on Carbon Sequestration and Climate Change Mitigation in Agriculture

Publication date:

2010

Document version

Publisher's PDF, also known as Version of record

Citation for published version (APA):

Wang, Y., Liu, F., Andersen, M. N., \& Jensen, C. R. (2010). Carbon Retention in the Soil-plant System under different Irrigation Regimes. In Proceedings: the 2nd International Workshop on Carbon Sequestration and Climate Change Mitigation in Agriculture (pp. 31) 


\section{The $2^{\text {nd }}$ International Workshop on Carbon Sequestration and Climate Change Mitigation in Agriculture}

\section{Proceedings}

Organizer Institute of Agricultural Resources and

Regional Planning (IARRP), Chinese

Academy of Agricultural Sciences (CAAS)

China Agricultural University (CAU)

Plant Nutrition and Fertilizer Society of China Soil Science Society of China (SSSC)

June 27-30, 2010

Beijing, China 


\title{
Carbon Retention in the Soil-plant System under Different Irrigation Regimes \\ Yaosheng Wang ${ }^{1 *}$, Fulai Liu ${ }^{1}$,Mathias N. Andersen ${ }^{2}$, Christian R. Jensen ${ }^{1}$ \\ 1.Department of Agriculture and Ecology, Faculty of Life Sciences, University of Copenhagen, Højbakkegaard Allé 13, DK-2630 Taastrup, Denmark \\ 2.Department of Agroecology and Environment, Faculty of Agricultural Sciences, University of Aarhus, P.O. Box 50, DK-8830 Tjele, Denmark \\ "Corresponding E-mail: yawa@life.ku.dk
}

\begin{abstract}
The effects of elevated $\mathrm{CO} 2$ concentration in the atmosphere on global warming have attracted increased attention into the research for enhancing carbon (C) sequestration in the ecosystems. Irrigation management is a potential strategy to reduce $\mathrm{C}$ emissions from agriculture by increasing $\mathrm{C}$ retention in the plant biomass. In addition, declining freshwater resources has stimulated research into developing novel irrigation strategies aiming at improving crop water use efficiency (WUE). Alternate partial root-zone irrigation (PRI) is a novel water-saving irrigation strategy being intensively studied in many courtiers and have been shown great potential to increase WUE as compared with full irrigation (FI) and deficit irrigation (DI) treatments. Besides saving irrigation water, PRI induced drying and wetting cycles of the soils could, however, cause the 'Birch effect' resulting in a flush of $\mathrm{C}$ and $\mathrm{N}$, which may lead to greater $\mathrm{C}$ losses from the soils. Therefore, the objective of this study was to investigate the effects of different irrigation regimes on $\mathrm{C}$ retention in the soil-plant system in order to evaluate their environmental impacts. Tomato plants were grown in split-root pots in a climate-controlled glasshouse and were subjected to FJ, DI and PRI treatments. Results showed that the concentration and the amount of total $\mathrm{C}$ in the soil were lower in FI and PRI as compared to DI, whereas the total C concentration in the PRI piants was significantly higher than FI and DI plants. Consequenily, the total amount of $\mathrm{C}$ retained in the soil-plant system was the highest in FI and was similar for PRI and DI treatments.
\end{abstract}

Keywords: Carbon sequestration, Deficit irrigation, Partial root-zone drying, Water use efficiency 